\title{
EAl Endorsed Transactions

\section{Experimental Validation of a Three-Phase Induction Motor Operating with a Three-Phase Bidirectional Variable Speed Drive}

\author{
Luis Machado, ${ }^{1, *}$, Tiago J. C. Sousa ${ }^{1}$, Delfim Pedrosa ${ }^{1}$, Vitor Monteiro ${ }^{1}$, J. G. Pinto ${ }^{1}$ and Joao L. Afonso ${ }^{1}$ \\ ${ }^{1}$ Centro ALGORITMI, University of Minho, Campus de Azurém, Guimarães, Portugal
}

\begin{abstract}
The three-phase induction motor is the main electric motor used in industrial applications, contributing significantly to the industrial electricity consumption. Additionally, the traditional variable speed drivers, due to the internal constitution based on a passive rectifier, contribute to accentuate power quality problems on the grid side. In this context, this paper presents the simulation, implementation and subsequent experimental verification of an electronic variable speed drive for three-phase induction motors, which is composed by a three-phase ac-dc converter on the grid side and by a three-phase dc-ac converter on the motor side. With the proposed solution, besides driving the motor, it is possible to mitigate power quality problems on the grid side (e.g., current harmonics and reactive power) associated with the use of diode-bridge ac-dc converters in the conventional variable speed drives. Besides, with the proposed solution, a bidirectional operation is possible, allowing to deliver to the power grid the energy generated in motor braking processes. As demonstrated along the paper, with the proposed variable speed drive it is possible to control the motor speed (including the rotation direction), and to achieve operation with sinusoidal currents and unitary power factor on the grid side. A laboratory prototype was developed, allowing to perform experimental validation and to verify the main functionalities of the variable speed drive.
\end{abstract}

Keywords: Active Rectifier, Induction Motor, Power Quality, Regenerative Braking, Variable Speed Drive (VSD).

Received on 05 September 2020, accepted on 27 December 2020, published on 14 January 2021

Copyright (C) 2021 Luís Machado et al., licensed to EAI. This is an open access article distributed under the terms of the Creative Commons Attribution license, which permits unlimited use, distribution and reproduction in any medium so long as the original work is properly cited.

doi: 10.4108/eai.14-1-2021.168137

"Corresponding author. Email: 1machado@dei.uminho.pt

\section{Introduction}

Nowadays, the three-phase induction motor with squirrel cage rotor represents more than $90 \%$ of the electric motors used in industry [1], contributing to about $70 \%$ of the industrial electricity consumption [2]. This situation occurs, not only because the induction motors present low acquisition and maintenance costs and great robustness, but mainly due to constant technological evolution and the development of control techniques that have brought a wider variety of applications [3].

Some applications involving induction motors require adjustments of speed variation in their processes, either due to the need to drive variable loads or the need to optimize existing processes. The advances in power electronics technologies, especially in the power semiconductors field, allows a better controllability, contributing to improve the

voltage and frequency modulation, which are necessary conditions to control the induction motors. The variable speed drives (VSDs) are devices designed to control the speed and torque of an alternating current (ac) motor, which use power converters that, based on control algorithms, allow the synthesis of sinusoidal currents with adjustable parameters, such as amplitude and frequency $[4,5]$. This conversion process can be realized directly using an ac-ac converter. In relation to ac-ac converters, the best known are the cycloconverters and matrix converters, which can be found in [5]. The VSDs can present different topologies, however, normally they are composed by: rectifier, dc-link, inverter and control system [6-8].

Conventionally, VSDs for induction motors employ a diode bridge rectifier to provide power to the dc-link from the power grid. These types of rectifiers, as they behave as non-linear loads, consume currents with a high harmonic content, that is, currents with a high total harmonic 
distortion (THD), which in turn cause distortion of the power grid voltage waveform, contributing to a low power factor upstream of the rectifier $[5,6]$. As they do not control the input or output current, and since they do not control the dc-link voltage, they are categorized as passive converters. Besides, as they operate only in the first quadrant, in this type of rectifier, the power flows only from the power grid side to the motor side, so the energy produced by the motor in situations of braking, namely change of speed or direction of rotation, should be dissipated in a resistor or stored in energy storage elements, such as batteries or capacitors $[6,9]$.

In order to solve the power quality problems originated by the passive converters, traditional methods have been used, such as the application of passive inductive filters in series, or capacitive filters in parallel (or both) or the use of multi-pulse rectifiers $[5,10]$. Active power filters can be used to reduce harmonic current distortion through the production of compensating currents, in case of the shunt active power filter, and to reduce the harmonic voltage distortion through the production of compensating voltages, in the case of the series active power filter [11]. If joint current and voltage compensation is required, the unified power quality conditioner (UPQC) is a solution. Another way to reduce harmonic distortion is to use converters to improve the power quality. In the literature, these converters are called improved power quality converters (IPQCs). In [11] is presented a review about multi-pulse three-phase IPQC converters. Also, in [12] are approached IPQCs, where unidirectional and bidirectional three-phase power factor correction (PFC) rectifiers can be found. These rectifiers use pulse-width modulation (PWM) techniques to control fully-controllable power semiconductors, such as IGBTs, to dynamically change the waveform of the input current and, thus, reduce its harmonic distortion, contributing to an increase of the power factor close to the unit [9, 12-13].

Some PFC topologies are not regenerative and, in turn, do not allow to return power to the power grid, i.e., they do not allow the operation as inverter. Vienna rectifier is an example of this [14]. However, other PFC topologies allow bidirectional power flow and can be used in applications where it is intended to return energy to the power grid, e.g., during a braking situation, as it is, moreover, one of the focus topics of this paper. These rectifiers, also known in the literature as active rectifiers and active front-end, similarly to inverters, are distinguished according to the type of energy storage element that they have on the dclink, and can be classified as current source rectifiers (CSR) or voltage source rectifiers (VSR).

The interest for the ac against dc drive systems over the years, combined with the technological evolution verified in power electronics, as well as in microelectronics, has motivated the appearance and development of new technologies and methodologies for the induction motor control. Nowadays, the existing control methods are divided into two main groups: scalar control and vector control $[3,15,16]$. Scalar control is based on the steady state equations that result from the equivalent circuit of the motor and only considers the instantaneous electrical quantities of the stator (magnetic flux, currents and voltages). In turn, vector control is based on the dynamic spatial equations of the motor, where instantaneous electrical quantities are represented by vectors [3]. These control methods have different degrees of complexity and the choice for each depends, essentially, on the accuracy, quickness and cost of the speed control system that is intended to be implemented.

Among the control methods for induction motors, the Volts per Hertz (V/f) is the most used, specifically the V/f control in open-loop. This is a type of control recommended for non-critical applications where speed and/or torque performances are not relevant [3]. When fast dynamic responses and high torque and speed accuracy are desired, the control method recommended in the literature is the vector control $[17,18]$. This type of control can be implemented in different ways, being the field-oriented control (FOC) and the direct torque control (DTC) the most widespread vector control techniques in the literature. In [19] a comparative study between these two control methods is presented. Most of control methods for induction motors require precise speed measurement, which is one of the indispensable requirements when robust, high-precision controls are required [3]. Obtaining this measurable parameter can easily come from reading sensors such as encoders or tachometers. However, the choice of such equipment raises the cost of the VSDs, increases the complexity at the hardware level and makes the system less reliable, which requires regular maintenance $[18,20]$. One way to overcome the problems underlying the use of the aforementioned sensors is to estimate the speed using instantaneous electrical quantities of the stator. The control techniques that use these estimators to obtain the velocity are usually known as sensorless control techniques. Some methods for estimating speed can be found in [18, 20, 21].

An active rectifier is proposed in [22-25] to interface the induction motor drive with the power grid. In [26] the authors proposed a VSD with an active rectifier to control the input current, assuring a high power factor and, with this, decreasing the circulating current harmonics in the motor inverter. In [27] and [28], a VSD with active rectifier was implemented to reduce the common mode voltage caused by different switching frequencies of the rectifier and the inverter. In [29], [30], and [31] a drive system uses an active rectifier, not only to mitigate power quality problems in the power grid side, but also to allow the regenerative energy recovery in motor braking situations, improving the system efficiency. In [32], an active rectifier was added to a VSD system, with a diode full-bridge rectifier, to improve the properties and characteristics of the proposed VSD, which operates as an active power filter for power quality improvement of the power grid side and to make feasible additional functions, such as regenerative braking.

The focus of this paper is the development of a VSD that allows the speed and direction control of an induction motor, as well as its smooth start and stop. A bidirectional 
power flow between the power grid and the induction motor is also a desired characteristic for the VSD, so that the kinetic energy generated by the motor in a braking situation can be delivered to the power grid, thus enabling regenerative breaking. In any of the operating situations (traction or braking) the VSD must operate without causing any power quality problems for the power grid side.

This paper is an extension of [33] and is structured as follows: Section 2 presents the braking techniques applicable to induction motors; Section 3 presents the electrical model of the proposed system; Section 4 presents the implemented control algorithm for each of the power converters; Section 5 shows the simulation results of proposed VSD; in Section 6 is described the developed prototype and the obtained experimental results of the VSD and Section 7 ends the paper with the main work conclusions.

\section{Review on Braking Systems for Electric Motors}

In many applications, one of the most important requirements in motor drive systems is braking [34]. In industrial applications, e.g., there is a need to quickly put the motor at rest, not only to keep it immobilized after the end of some process, but also to safeguard products in situations of defective operation, or in emergency situations in order to preserve the physical integrity of the operator as well as the equipment. Depending on the application in which it is inserted, the drive system may be subject to frequent starting, stopping or reversing directions of rotation, causing the efficiency of the system to decrease considerably [35].

Braking is an energy conversion process aimed at removing or attenuating the mechanical energy of a moving system with a view to decelerating or immobilizing it. According to [34], this can be done in two ways: mechanically, through brakes whose objective is to increase the frictional forces, thus converting the mechanical energy into heat, causing the deceleration of the system; and electrically, through the application of an electromagnetic force that opposes the rotation of the motor, and the energy can be dissipated in the form of heat in the motor itself or in resistances, called braking resistors, or it can be regenerated, being returned to the power supply or stored in an energy storage element. In [34] the following electric braking methods are presented: (1) reverse current braking; (2) dynamic braking; (3) regenerative braking.

The reverse current braking, also known in the literature as plugging, is especially useful for quickly stopping or reversing the direction of rotation of the motor and is achieved by changing two of the three phases that feed the stator windings [34, 36].

The dynamic braking technique is widely used in industrial applications and consists of a process in which the kinetic energy of the rotor is thermally dissipated in a resistor, after interruption of the supply to the stator $[34,36]$. Once without power into the stator, the inertia of the motor and the load keeps the rotor in rotation, with magnetic flux production in the stator windings, in which, by the electromagnetic induction phenomenon, a voltage appears at its terminals. The asynchronous machine works as a generator, transferring to the stator the kinetic energy in form of electrical energy. Combining this fact with a system that dissipates that energy, the dynamic braking method becomes conceivable. The dynamic braking can be implemented in different ways. In [34] several methods of dynamic braking are briefly presented.

The kinetic energy resulting from a braking process does not necessarily need to follow a dissipative process, that is, to be converted into heat. This can be converted into electrical or mechanical energy [37]. There are several applications where the energy resulting from the inertia of the motor is used, bringing significant benefits to the system in terms of energy use. An example of this is the kinetic energy recovery system (KERS), used in automotive braking systems that recover part of the kinetic energy generated by the vehicle deceleration/braking $[38,39]$. In the case of vehicles with an internal combustion engine, this energy can be stored mechanically on a flywheel, as is the case with the KERS systems produced by the company Flybrid, originally developed for Formula 1 cars, but which are also already part of the braking control systems of other vehicles, such as trucks, buses and locomotives, where starting and stopping operations are frequent, and there is an enormous potential for reusing energy that would be lost without the use of such

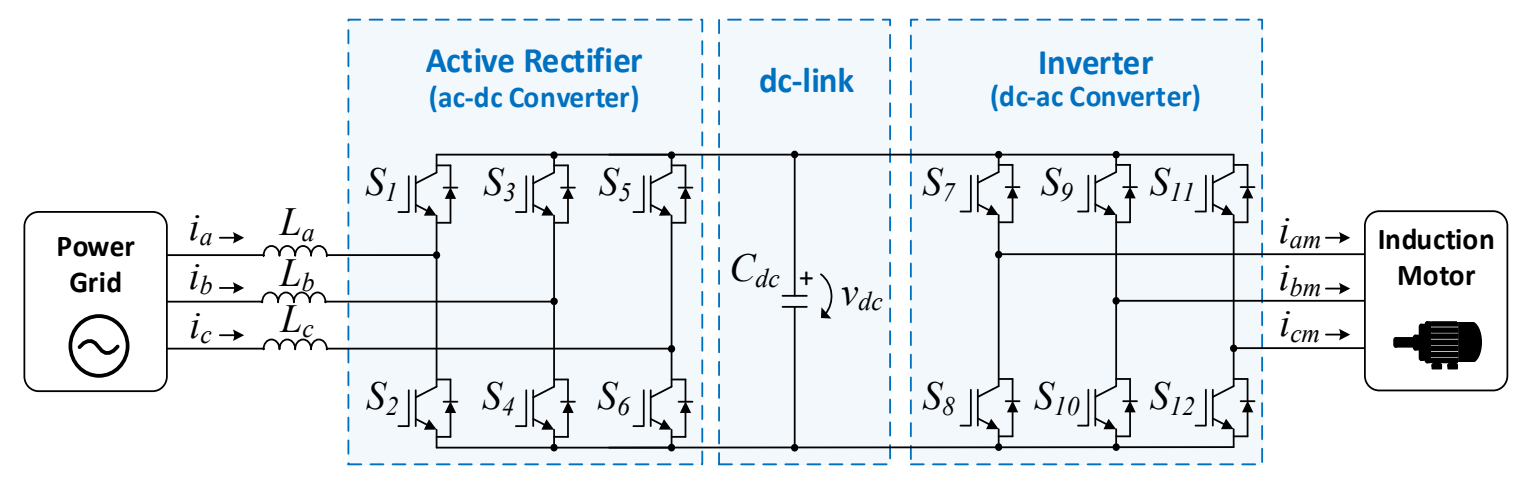

Figure 1. Proposed system for the VSD. 
recovering energy systems [39]. Regarding electric vehicles, kinetic energy can be converted into electrical energy during braking and later stored in energy storage elements such as batteries or capacitors $[40,41]$. This is a technology widely used in hybrid vehicles, as it contributes to the reduction of fuel consumption and greenhouse gas emissions [41].

Applications where the use of kinetic energy resulting from a regenerative braking process can be applied are not limited to road vehicles. Applications such as elevators or cranes, where electric motors can function as generators, even for short periods of time, are common in everyday activities, and energy regeneration in these cases can represent significant energy savings [35]. In addition, in systems with regenerative braking technologies, the amount of heat released is less than that observed in systems without this type of associated technology, which in some cases allows, in addition to a better use of energy, a reduction in costs associated with the cooling system.

\section{Proposed System}

This section presents the electrical model of the proposed system under analysis in this paper. As previously mentioned, a typical topology of a VSD for three-phase induction motors, usually, has a diode bridge rectifier for interfacing with the power grid, also known in the literature as a Graetz bridge [6]. As a disadvantage, this type of converter does not control the input (nor the output) current nor the dc-link voltage $\left(v_{d c}\right)$, which is limited to the peak value of the power grid line-to-line voltages. In this way, the proposed system suggests the exchange of the passive semiconductors by active semiconductors, resulting in the electric model of Figure 1. In this figure, two voltage source converters (active rectifier and inverter) can be seen, both with three legs with two insulate gate bipolar transistors (IGBTs) in each leg. The fact that this topology has only three wires allows to simplify the solution and reduce the costs related with the addition of a third IGBT leg for the neutral connection or, if it is connected to the midpoint of the dc-link capacitors, reduce the complexity associated with the voltage regulation in each capacitor terminals.

The converters are connected through a dc-link consisting of a capacitive filter $\left(C_{d c}\right)$, whose function is to minimize the ripple of the dc-link, $v_{d c}$, voltage. At the input of the active rectifier, coupling inductors $\left(L_{a}, L_{b}, L_{c}\right)$ are used to smooth the ripple in absorbed currents $\left(i_{a}, i_{b}\right.$, $\left.i_{c}\right)$. The stator windings of the induction motor smooth the currents ripple at the output of the inverter $\left(i_{a m}, i_{b m}, i_{c m}\right)$, and so, no output filter is required.

\section{Control Algorithm}

This section presents the control algorithm implemented for the proposed solution. For a better understanding, it is divided into two parts: control for the active rectifier and control for the traction system, which involves the inverter and motor.

\subsection{Active Rectifier}

The block diagram of the strategy used to control the active rectifier can be seen in Figure 2. In this control strategy, the dc-link voltage $\left(v_{d c}\right)$ is measured and compared to the reference value $\left(v_{d c_{-} r f}\right)$, from where results the error signal $v_{d c_{-} e r}$, which is submitted to a proportional-integral controller (PI). Posteriorly, the output of this controller is multiplied by each of the sinusoidal references $\left(p l l_{a}, p l l_{b}\right.$, $p l l_{c}$ ) with unitary amplitude and frequency and phase equal to the fundamental component of the respective power grid voltage. These references are obtained from the $\omega t$ angle

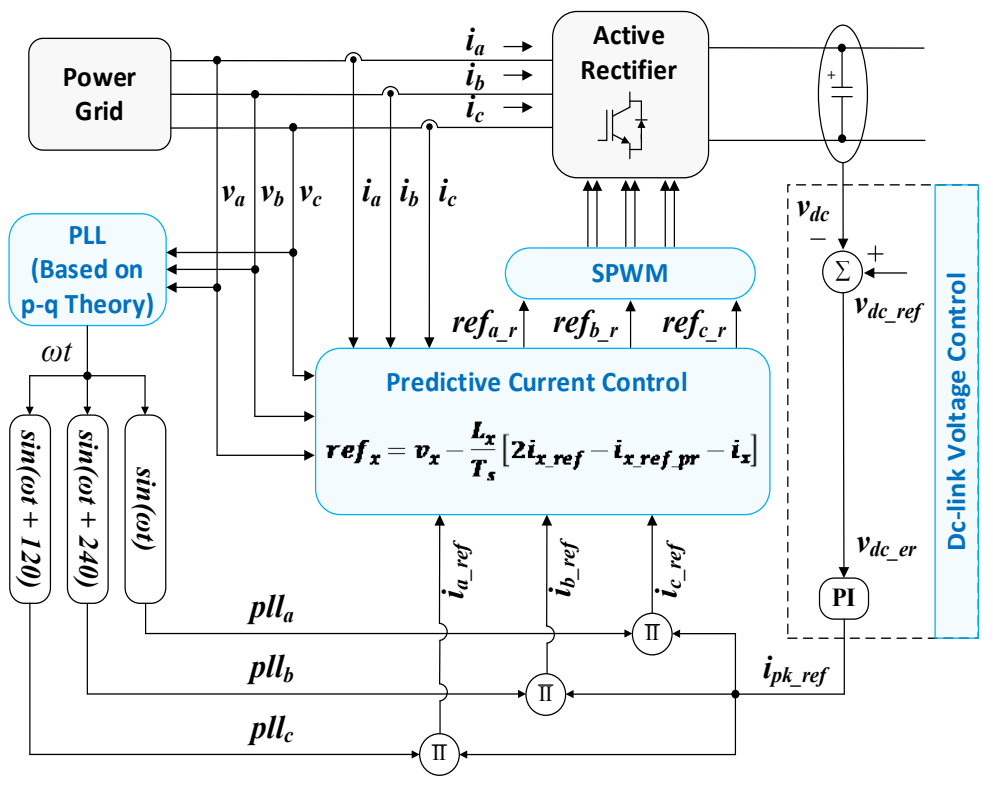

Figure 2. Control diagram for the rectifier stage of the VSD. 
resulting from the phase locked-loop (PLL) based on the $p-q$ theory [42-46], corresponding to three sinusoidal signals with frequency synchronized with the frequency of power grid voltage and amplitude $i_{p k}$ ref dependent of the error and the gains of the PI controller. The currents $i_{a-r e f}$, $i_{b \text { ref }}$ and $i_{c \text { ref }}$ are the reference currents for each input currents $\left(i_{a}, i_{b}, i_{c}\right)$. The reference voltages in instant $n$ $\left(r e f_{x}[n]\right)$, i.e., the reference voltage that the converter must produce in phase $x$, are calculated using a predictive control technique [47-50], as represented by equation (1), which is calculated based on the line-to-neutral power grid voltage $\left(v_{x}[n]\right)$, the coupling inductance value per phase $\left(L_{x}\right)$, the sampling time $\left(T_{S}\right)$, the phase current measured at the input of the rectifier $\left(i_{x}[n]\right)$, its reference current $\left(i_{x \text { ref }}[n]\right)$ and the current measured at the previous instant $\left(i_{x}\right.$ ref $\left.[n-1]\right)$.

$$
r e f_{x}[n]=v_{x}[n]-\frac{L_{x}}{T_{s}}\left[2 i_{x_{-} r e f}[n]-i_{x_{-} e f}[n-1]-i_{x}[n]\right]
$$

From the reference signals, in order to generate the appropriate duty-cycle of the pulses to be applied to the gates of the IGBTs, the sinusoidal pulse-width modulation (SPWM) method was used.

\subsection{Motor Control}

For the motor control, the closed-loop Volts per Hertz control was chosen. Compared to vector control techniques, it is simpler, more economical and easier to implement [51-54], and is recommended for non-critical applications where good speed and/or torque performances are not relevant [3].

Figure 3 shows the designed block diagram of the control loop implementation for the traction system. As it can be seen, the rotor speed, $\omega_{r}$, is compared with the reference speed $\omega_{r_{-} \text {ref }}$ from where, by application of a PI controller, a signal $\left(\omega_{d}\right)$ is obtained, which has to be added to the rotor speed in order to obtain the desired synchronous speed $\left(\omega_{s_{r} r e f}\right)$. Once calculated $\omega_{s_{-} r e f}$, and, based on this, calculated $f_{s_{-} \text {ref }}$ through a pre-established $\mathrm{V} / \mathrm{f}$ ramp, the respective voltage amplitude $\left(v_{s_{-}} r\right)$ that must be applied to each of the stator windings is obtained by equation (2).

$$
V_{s_{-} \text {ref }}=\frac{V_{s}}{f_{\text {nom }}} f_{s_{-} \text {ref }}
$$

On the other hand, the integration of $\omega_{s_{-} \text {ref }}$ results in the signal $\theta_{\text {ref }}$ that defines the frequency of the reference voltages, obtain by equation (3), that must be synthesized and subsequently applied to a modulation technique. As in the control of the active rectifier, the modulation technique used in the inverter control was SPWM.

$$
v_{\text {ref } x}=V_{s_{-} \text {ref }} \sin \left(\theta_{\text {ref }}-k_{x}\right)
$$

\section{Simulation Results}

This section presents the simulation results obtained for the joint operation of the two power stages, rectifier and inverter, which allows to validate the integral functioning of the VSD for different operating situations. The electric motor with which it is intended to validate the proposed VSD (presented in Figure 1) is a three-phase induction motor with a squirrel cage rotor, with a nominal power of $5.5 \mathrm{~kW}$. The parameters that characterize it were obtained from its nameplate, which can be seen in Table 1.

Figure 4 shows the dc-link voltage $\left(v_{d c}\right)$ and the motor speed evolution during the operating stages of the proposed VSD, which range from the pre-charge of the dc-link capacitors to the starting of the inverter operation for induction motor drive with a coupled load of $40 \mathrm{Nm}$. The inverter operation starts only after the defined time $(1 \mathrm{~s})$ for

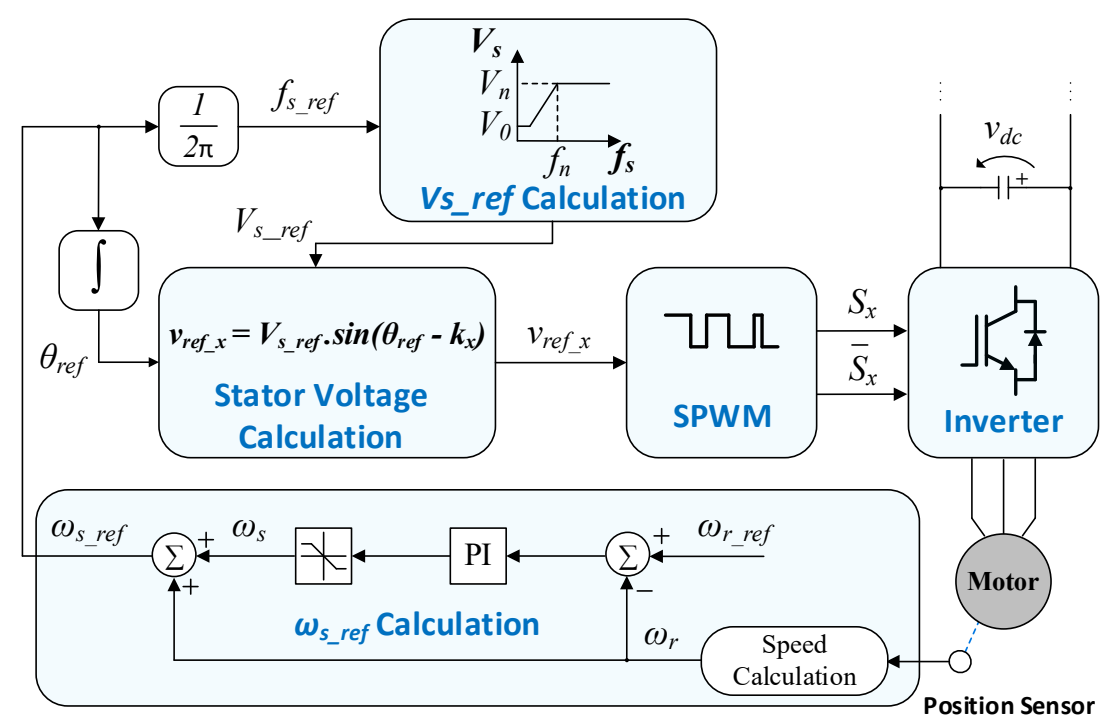

Figure 3. Control diagram for the inverter stage of the VSD. 
(a)

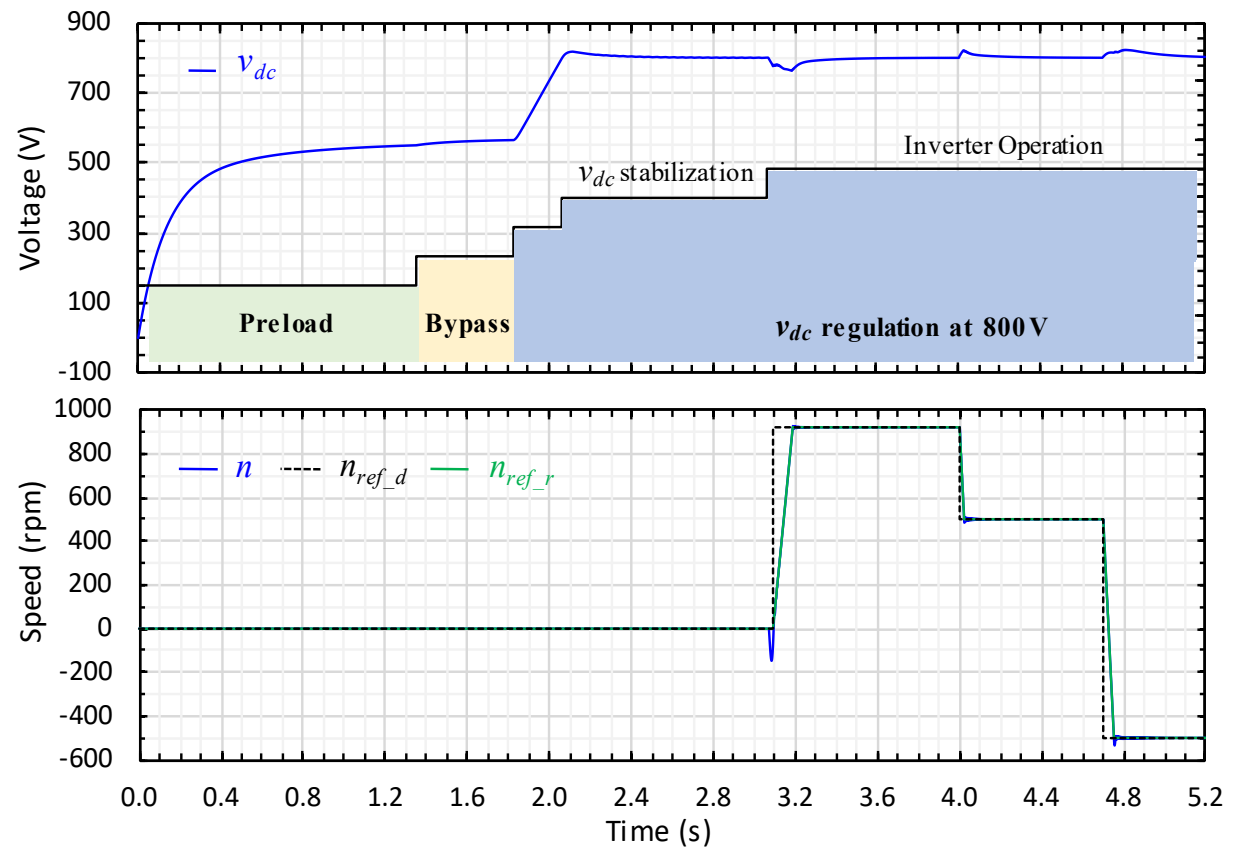

Figure 4. Simulation results of the VSD operating stages for driving an induction motor with a coupled load of $40 \mathrm{Nm}$ : (a) dc-link voltage $\left(v_{d c}\right)$ evolution; (b) motor speed $(n)$ evolution for different reference speeds.

stabilizing the dc-link voltage $\left(v_{d c}\right)$ has ended. This occurs, approximately, in the instant $3.1 \mathrm{~s}$. Shortly thereafter, the induction motor starts with a $40 \mathrm{Nm}$ coupled constant load. Table 2 shows the reference speeds $\left(n_{\text {ref }} d\right)$ used in the simulations, which were provided to the motor in the ramp form $\left(n_{\text {ref } \_}\right)$.

Table 1. Technical data of the three-phase induction motor used.

\begin{tabular}{ll}
\hline Parameter & Value \\
\hline Nominal power & $5.5 \mathrm{~kW}$ \\
Nominal speed & $920 \mathrm{rpm}$ \\
Pole number & 6 \\
Nominal voltage & $400 \mathrm{~V}$ \\
Nominal torque & $57.1 \mathrm{Nm}$ \\
Nominal current $\left(I_{n}\right)$ & $12.32 \mathrm{~A}$ \\
Start current & $5.8 \mathrm{In}_{n} \mathrm{~A}$ \\
Nominal frequency & $50 \mathrm{~Hz}$ \\
Cos $\varphi$ & 0.77 \\
Efficiency & $87 \%$ \\
\hline
\end{tabular}

Figure 5 shows the currents absorbed by the motor $\left(i_{a m}, i_{b m}\right.$ and $\left.i_{c m}\right)$ and by the rectifier $\left(i_{a}, i_{b}\right.$ and $\left.i_{c}\right)$ for two of the operating situations showed in Figure 4, which are related to the motor traction at the nominal speed of $920 \mathrm{rpm}$ (Figure 5 (a)) and at the moment immediately after the rotation inversion, which occurs after the time
$4.7 \mathrm{~s}$ (Figure $5(\mathrm{~b})$ ). As can be seen in Figure 5 (a), during traction, sinusoidal currents in phase with the power grid voltages are consumed, as shown in the graph showing current $\left(i_{a}\right)$ and voltage $\left(v_{a}\right)$ for phase a on the grid side. In Figure 5 (b), the currents consumed by the motor are shown with the sequence $i_{a m}, i_{c m}, i_{b m}$, resulting from the exchange of two of the phases that supply the motor (reverse current braking) carried out by the control system after order for reversing the motor rotation when the motor speed was $500 \mathrm{rpm}$. As a result of this braking, the $v_{d c}$ voltage exceeds the reference value $(800 \mathrm{~V})$, causing sinusoidal currents to be synthesized in opposition phase to the respective power grid voltages, thus enabling the current injection in the power grid and, consequently, energy regeneration.

Table 2. Reference speeds supplied to the VSD controller when driving a $40 \mathrm{Nm}$ load.

\begin{tabular}{ll}
\hline Speed $(\mathbf{r p m})$ & Time Interval \\
\hline 920 & $3.07 \mathrm{~s}$ to $4 \mathrm{~s}$ \\
500 & $4 \mathrm{~s}$ to $4.7 \mathrm{~s}$ \\
-500 & $4.7 \mathrm{~s}$ to $5.2 \mathrm{~s}$ \\
\hline
\end{tabular}

\section{Experimental Setup and Results}

This section presents the obtained experimental results of the developed VSD prototype (Figure 6), which was 

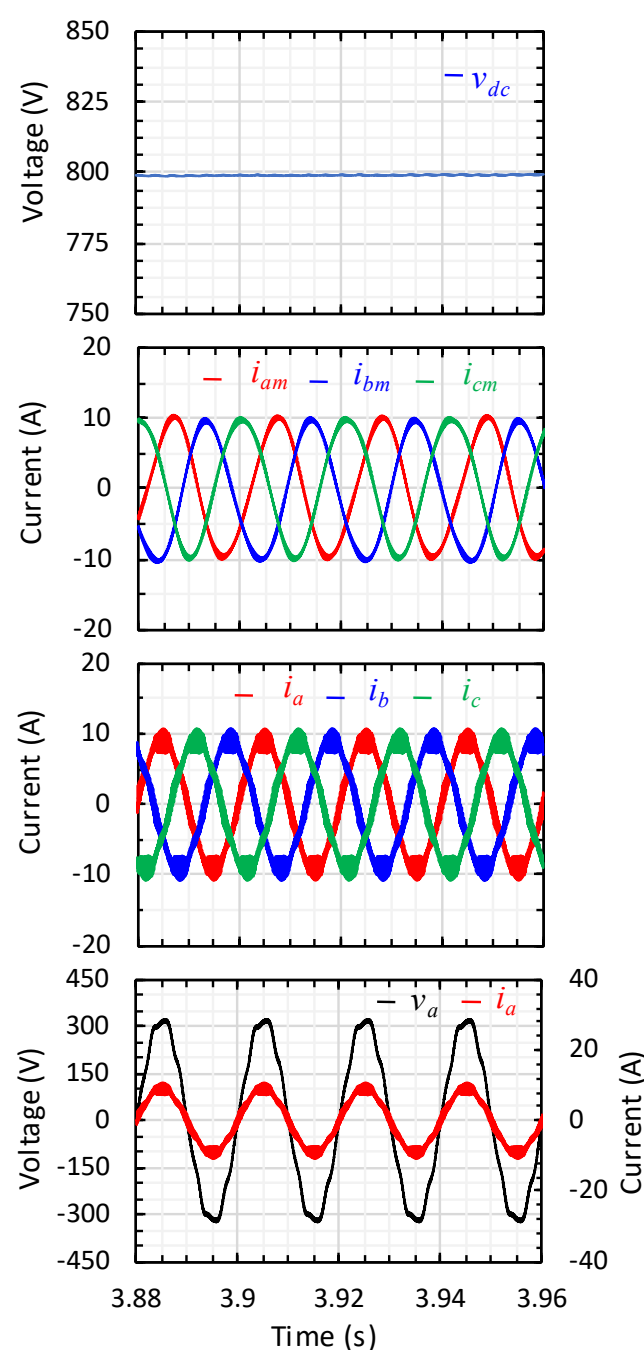

(a)
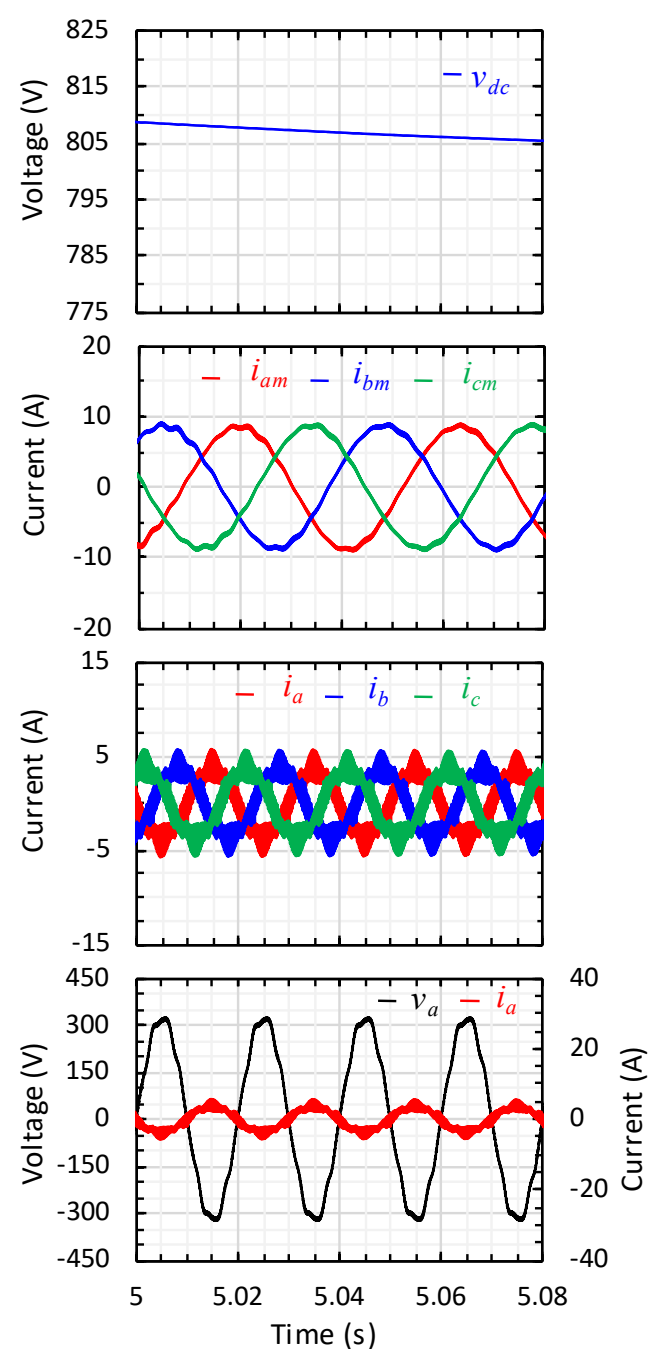

(b)

Figure 5. Simulation results obtained for dc-link voltage $\left(v_{d c}\right)$, currents absorbed by the motor $\left(i_{a m}, i_{b m}, i_{c m}\right)$ and at the rectifier input $\left(i_{a}, i_{b}, i_{c}\right)$ in two operational situations: (a) motor traction with a load of $40 \mathrm{Nm}$ at a speed of $920 \mathrm{rpm}$;

(b) regenerative braking moments after reversing of motor rotation speed from $500 \mathrm{rpm}$ to $-500 \mathrm{rpm}$.

developed according to the topology presented in Figure 1. At the top of the prototype, the two power converters can be seen, implemented with six SKM400GB12V half-bridge IGBT modules from Semikron. Each half-bridge is driven by a SKHI22AR driver, also from Semikron. For all IGBTs, a $5 \mathrm{kHz}$ switching frequency was used. The dc-link, also at the top, is built by a set of capacitors with a total capacitance of $5.5 \mathrm{mF}$ and a maximum voltage of $900 \mathrm{~V}$. Immediately below of the power converters, can be seen the sensors used to measure the system variables, as well as the dc-link protections for overvoltages above $900 \mathrm{~V}$. Further down, on the left, it can be seen the control system platform, based on a TMS320F28335 DSP from Texas Instruments, and, on the right, can be found the coupling inductors for the active rectifier. At the bottom of the prototype stands all the necessary logic for the pre-charger system of the dc-link capacitors and the prototype interface with the power grid.

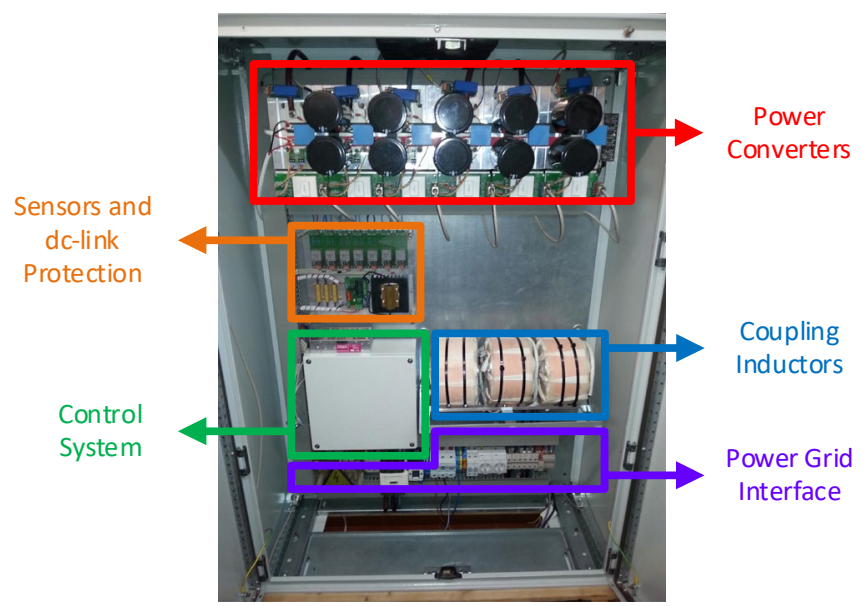

Figure 6. Laboratory prototype of the developed VSD. 
The experimental results for the motor control were obtained with an induction motor JM 132M2 from Seipee, whose characteristics are specified in Table 1. Figure 7 shows the workbench on which the experimental tests for the VSD prototype were made. In this figure, in addition to essential laboratorial equipment, such as dc power supplies and an oscilloscope, it can be seen the induction motor coupled to an electromagnetic brake, which allows testing the motor for different values of mechanical load up to a maximum resistive torque of $52 \mathrm{Nm}$ [55].

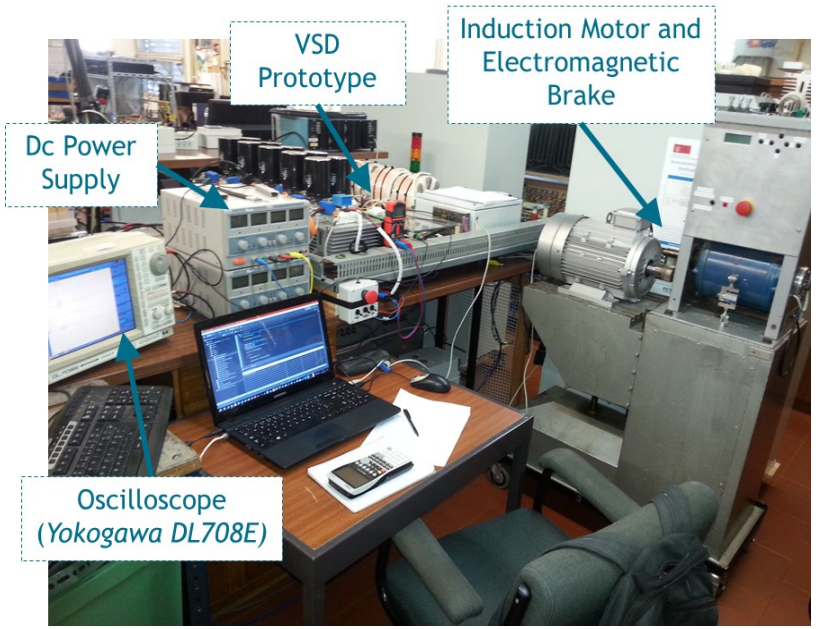

Figure 7. Workbench for experimental tests of the VSD prototype.

\subsection{Active Rectifier Results}

The experimental results concerning the operation of the active rectifier were obtained based on the scheme of Figure 8. As it can be seen, the power grid voltage is reduced from root mean square (rms) value of $230 \mathrm{~V}$ to $75 \mathrm{~V}$ by using a group of three single-phase starconnected transformers. In the dc-link, a resistive load $\left(R_{\text {load }}\right)$ of $25 \Omega$ was placed in series with a circuit breaker, it can be connected or disconnected from the dc-link at certain moment. With this, it was intended to validate the control of the dc-link voltage and simultaneously the predictive current control. The inductance value $\left(L_{a}, L_{b}\right.$,
$L_{c}$ ) of each coupling inductor, the equivalent capacitance value $\left(C_{e q}\right)$ and the equivalent equalization resistance $\left(R_{e q}\right)$ of the dc-link are, respectively, $5 \mathrm{mH}, 5.5 \mathrm{mF}$ and $8.4 \mathrm{k} \Omega$.

With the dc-link voltage regulated at $250 \mathrm{~V}$, at a certain moment, the load of $25 \Omega$ was connected (Figure 9 (a)), with an expected drop in dc-link voltage. In steady state, the grid currents $\left(i_{a}, i_{b}, i_{c}\right)$ were obtained in the three phases with amplitude of $17 \mathrm{~A}$, in phase with the respective line-to-neutral power grid voltages $\left(v_{a}, v_{b}, v_{c}\right)$ (Figure 9 (b)). These currents have a total harmonic distortion (THD) in relation to the fundamental component of $1.6 \%, 1.4 \%$ and $1.7 \%$ for phases $a, b$ and $c$, respectively.

In order to validate the operation of the ac-dc converter as an inverter, a dc-link voltage of $120 \mathrm{~V}$ was fixed with a voltage source. Due to the modulation index used (85\%) and to the available voltage sources, it was necessary to reduce to the power grid voltage, having been changed to $25 \mathrm{~V}$ rms. Results were obtained for peak currents reference of $1 \mathrm{~A}$ (Figure 10 (a)) and $2 \mathrm{~A}$ (Figure 10 (b)). With these results, it was verified that the harmonic distortion of the currents injected into the power grid is greater when the amplitude of the currents is smaller, which is expected, considering that the signal-to-noise ratio is lower in this case.

\subsection{Motor Control Results}

The experimental results for the motor control were obtained with the induction motor presented in Figure 7.

In order to carry out the experimental tests, the dc-link was, in a first moment, fed from the power grid through the reverse diodes of each of the fully controllable semiconductors of the rectifier stage (Figure 11). Thus, the grid voltage $(75 \mathrm{~V} \mathrm{rms})$ was rectified, resulting in a dc-link voltage close to the peak value of the line-to-line voltages, which is slightly lower due to voltage drops in the coupling inductors, voltage drops on the diodes of the converter and also due to the equivalent resistance value of $8.4 \mathrm{k} \Omega$ on the dc-link which, although not properly low, is not negligible.

In the first test, the induction motor was subjected to a constant load of $3 \mathrm{Nm}$ at different reference speed values $\left(n_{r e f}\right)$ and the experimental result of Figure 12 (a) was

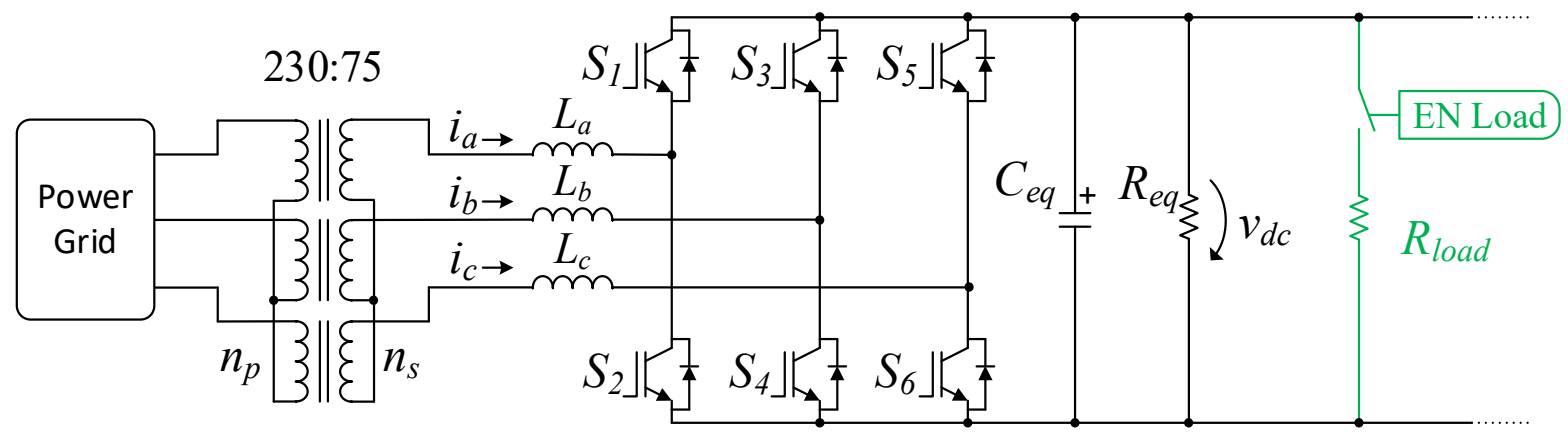

Figure 8. Power circuit used to obtain the experimental results of the VSD active rectifier. 
obtained. As it can be seen, initially, the motor was rotating with a speed $(n)$ of $200 \mathrm{rpm}$ in a given direction. After about $1 \mathrm{~s}$ the direction of rotation was reversed. At this instant, as the figure shows, the reversal voltage braking was given until the speed is annulled, and the dc-link voltage was slightly increased. From this speed $(0 \mathrm{rpm})$, the motor accelerated until reaching the reference speed of $200 \mathrm{rpm}$, which took place after $2 \mathrm{~s}$. During this acceleration, as a consequence of the consumed currents $\left(i_{a m}, i_{b m}, i_{c m}\right)$ (about $15 \mathrm{~A}$ peak), the appearance of drop of approximately $23 \mathrm{~V}$ in the dc-link voltage is notorious.

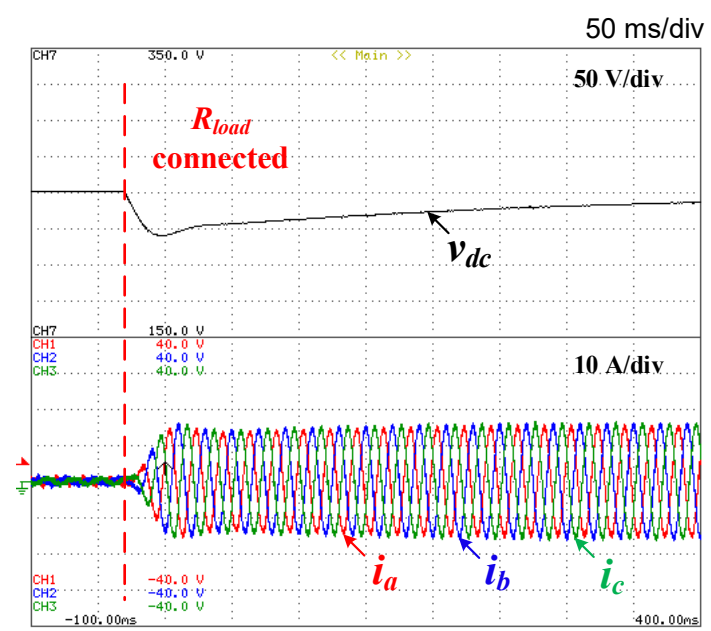

(a)

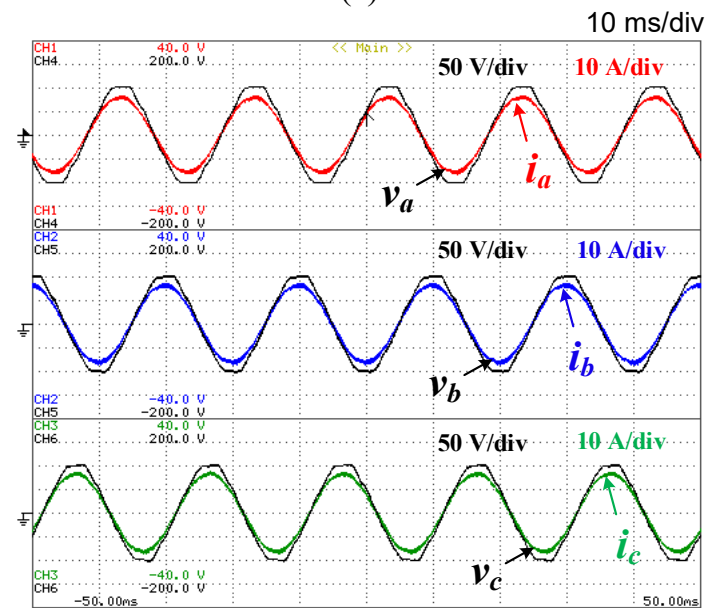

(b)

Figure 9. Experimental results of the active rectifier operation with a $25 \Omega$ load connected to the dc-link:

(a) Transient state dc-link voltage and power grid currents; (b) Steady state power grid voltages and currents.

Then, the behavior of the motor with an applied load torque of $5 \mathrm{Nm}$ was tested also for different rotation speeds. The result obtained is shown in Figure 12(b). During the first two seconds, an oscillation of the motor speed is visible around the reference speed of $400 \mathrm{rpm}$. This oscillation tends to decrease as the speed decreases, as it can be seen.
During the speed changes, it can be seen the charging of the dc-link capacitors, with a maximum voltage on the dc-link close to $240 \mathrm{~V}$ at the transition from $400 \mathrm{rpm}$ to $350 \mathrm{rpm}$. Since in these tests a diode bridge rectifier was used, the energy cannot flow to the power grid, so the energy generated by the motor during braking is stored in the dc-link capacitors. Posteriorly, the ca-cc converter was placed to function as the active rectifier. At this stage a load torque of $5 \mathrm{Nm}$ was applied to the motor shaft, and this was carried out at a speed of $600 \mathrm{rpm}$, which, after some time, was increased to $800 \mathrm{rpm}$. After that, the results Figure 13 (a) are presented, where the absorbed current in phase $a\left(i_{a}\right)$ and the respective line-to-neutral power grid voltage $\left(v_{a}\right)$ are shown. As can be seen, the current is in phase with the power grid voltage. It is also possible to see that the distortion of the current at the input of the rectifier $\left(i_{a}\right)$ tends to decrease with the increase of the current, as previously verified in the results obtained for the operation of the ac-dc converter as inverter.

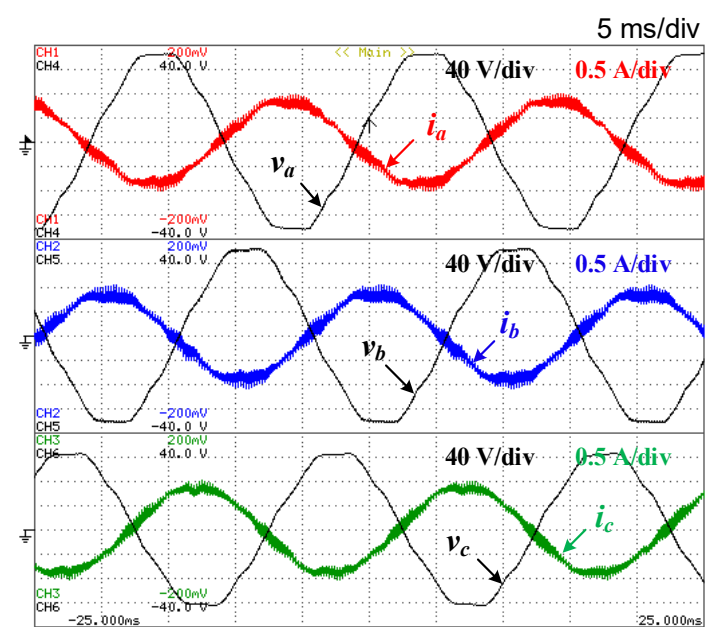

(a)

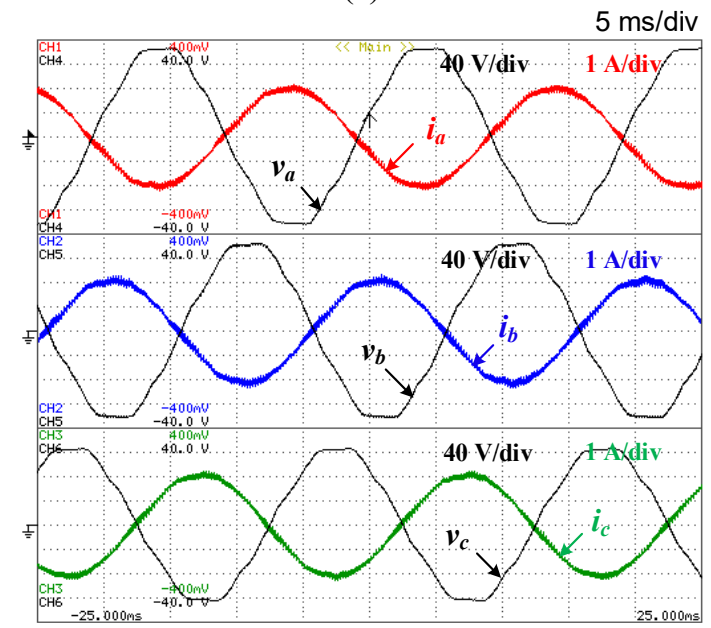

(b)

Figure 10. Experimental results of active rectifier operation delevering energy to the power grid: (a) reference currents of 1 A peak;

(b) reference currents of $2 \mathrm{~A}$ peak. 


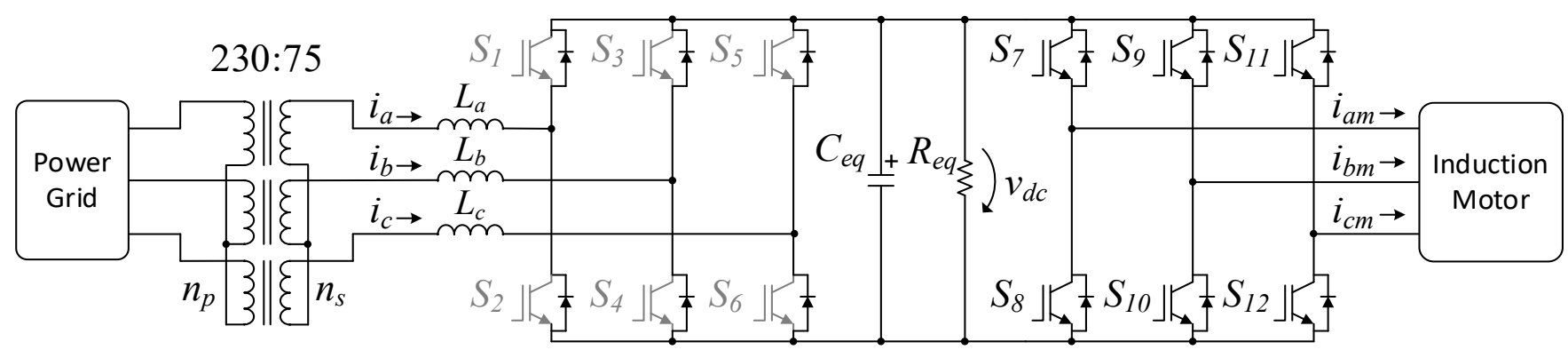

Figure 11. Power circuit used to obtain the experimental results to VSD.

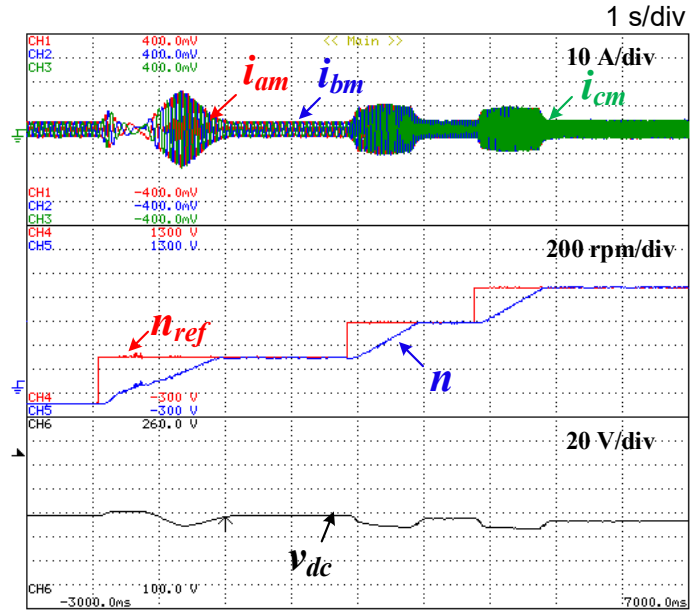

(a)

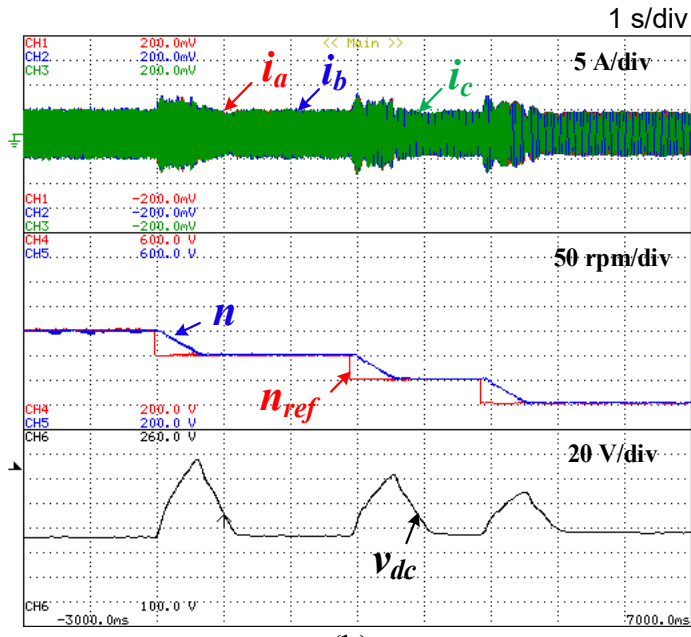

(b)

Figure 12. Results obtained in the operation of the motor for a constant load of: (a) $3 \mathrm{Nm}$; (b) $5 \mathrm{Nm}$.

Then, to analyze the behavior of the system in the event of motor deceleration, the speed of $800 \mathrm{rpm}$ was reduced again to $600 \mathrm{rpm}$ and the results of Figure 13 (b) were obtained. As it can be seen, the current at the input of the rectifier in phase $a\left(i_{a}\right)$ has become in phase opposition with the voltage $v_{a}$, remaining in this situation for about four power grid cycles. During this time, the energy was injected into the power grid, therefore the ac-dc converter was used as an inverter. Also, for this situation, there was an increase of the dc-link voltage by about $14 \%$ of the voltage set for regulation $(250 \mathrm{~V})$.

\section{Conclusion}

This paper presents an analysis of a variable speed drive (VSD), which makes use of a three-phase ac-dc power converter to interface with the power grid, and a three-phase dc-ac converter to drive a three-phase induction motor, with both power converters sharing a capacitive dc-link. Initially, a review on braking systems for electric motors was presented, having been addressed some braking techniques, such as: Reverse Current Braking, which is especially suitable for applications that require rapid stopping of the motor or reversing the motor rotation direction; Dynamic Braking, where the energy produced during the motor braking is lost, dissipated in a resistor; and Regenerative Braking, where the electric energy produced can be stored and later used, or returned to the power grid, assuming this as an added value, in energetic terms, for electric traction systems. Then, an electrical model of the system was described, the control algorithms were explained and the simulation results presented. The obtained simulation results validate the correct control of the dc-link voltage, where the pre-charge stages of the dc-link capacitors, the bypass to the pre-charge resistors and the stage of regulation of the dc-link voltage were evaluated, having a reference value of $800 \mathrm{~V}$. The proposed VSD was simulated to validate the possible stages of operation (traction and braking), and to verify some functionalities, such as the motor rotation inversion and the regenerative braking method. It is observed that, during the traction and the braking operation, the current in the power grid side is sinusoidal and the power factor is almost unitary, as expected. Based on the proposed electrical models, a laboratory prototype was implemented, from which the experimental results presented in this paper were obtained. These results achieved the objective concerning the experimental validation of the proposed control algorithms, specifically the predictive current control (for the active rectifier operation) and the closed-loop Volts per Hertz (V/f) 


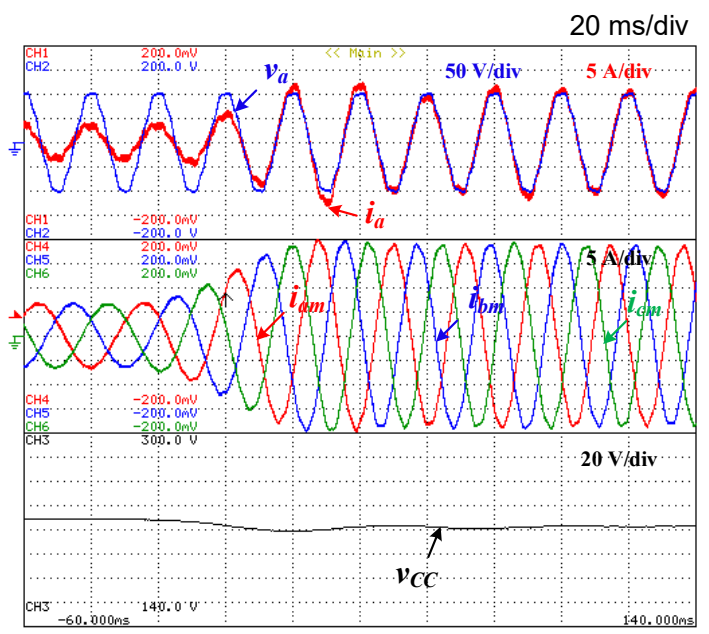

(a)

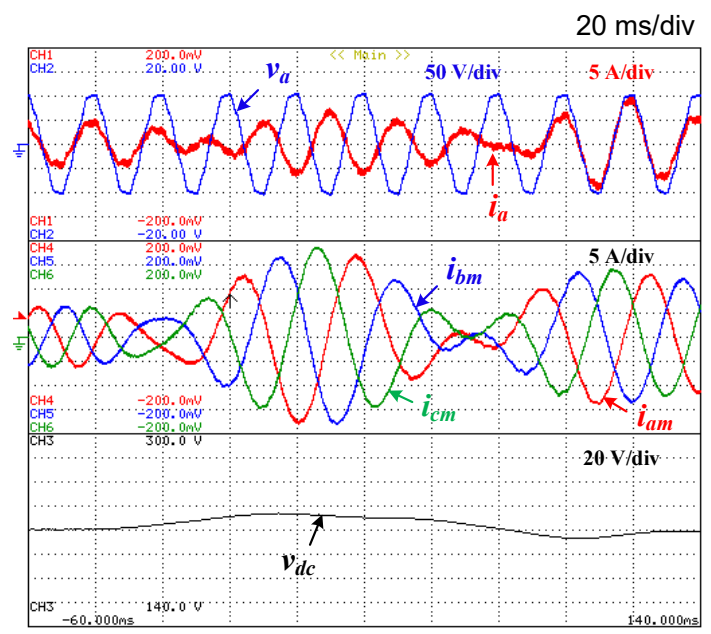

(b)

Figure 13. Experimental results obtained for the motor driving a $5 \mathrm{Nm}$ load during: (a) Acceleration from $600 \mathrm{rpm}$ to $800 \mathrm{rpm}$; (b) Deceleration from $800 \mathrm{rpm}$ to $600 \mathrm{rpm}$.

control (for the motor speed control). Thus, it was possible to verify the capability of the proposed system to avoid power quality problems, in particular, in relation to the currents consumed on the power grid side, which present almost sinusoidal waveforms and almost zero reactive power consumption (i.e., with low current harmonic content and almost unitary power factor). In relation to the motor control, its operation was validated in the traction mode, as well as in the braking mode, returning the generated energy to the power grid (regenerative braking), without neglecting the power quality of the power grid.

In terms of future work, there are some actions that can be considered to improve the work in progress, e.g., the energy regeneration can be analyzed regarding an economical profit compared with the traditional solution (i.e., without the ability to regenerate energy), as well as a comparison, between the presented control and a vector control technique (e.g., field-oriented control), in terms of performance.

\section{Acknowledgements.}

This work has been supported by FCT- Fundação para a Ciência e Tecnologia within the Project Scope: UIDB/00319/2020. This work has been supported by the FCT Project DAIPESEV PTDC/EEI-EEE/30382/2017, and by the FCT Project QUALITY4POWER PTDC/EEI-EEE/28813/2017.

\section{References}

[1] Chavhan, K., Ugale, R., "Automated test bench for an induction motor using LabVIEW", IEEE International Conference on Power Electronics, Intelligent Control and Energy Systems (ICPEICES), pp.1-6, Jul., 2016.

[2] Almeida, A., Fong, J., Falkner, H., Bertoldi, P., "Policy options to promote energy efficient electric motors and drives in the EU", Renewable and Sustainable Energy Reviews, vol.74, 1275-1286, 2017.

[3] I. Alsofyani and N. Idris, "A review on sensorless techniques for sustainable reliablity and efficient variable frequency drives of induction motors", Renewable and Sustainable Energy Reviews, vol.24, pp.111-121, Aug., 2013.

[4] S. Galceran, M. Teixidó, A. Sumper, J. Casas, and J. Sánchez, "Adjustable Speed Drives and Power Quality", Proceedings of the 10 Inter National Conference on Selective Modal Analysis with Applications to Electric Power Systems, vol.89, pp.926-938, Apr., 2003.

[5] M. Rashid, Power electronics handbook: devices, circuits and applications. Academic press, nov., 2006. ISBN: 9780080467658.

[6] R. Saidur, S. Mekhilef, M. Ali, A. Safari, and H. Mohammed, "Applications of Variable Speed Drive (VSD) in electrical motors energy savings", Renewable and Sustainable Energy Reviews, vol.16, pp.543-550, out., 2011

[7] S. Galceran, M. Teixidó, A. Sumper, J. Casas, and J. Sánchez, "Adjustable Speed Drives and Power Quality", Proceedings of the 10 Inter National Conference on Selective Modal Analysis with Applications to Electric Power Systems, vol.89, pp.926-938, Apr., 2003.

[8] A. Almeida, F. Ferreira, P. Fonseca, B. Chretien, H. Falkner, J. C. Reichert, M. West, S. B. Nielsen, and D. Both, "VSDs For Electric Motor Systems", Final Report, SAVE Programme, European Commission, Brussels, Feb., 2019.

[9] J. Rodriguez, J. Dixon, J. Espinoza, J. Pontt, and P. Lezana, "PWM Regenerative Rectifiers: State of the Art", IEEE Transactions on Industrial Electronics, vol.52, no.1, pp.5-22, Feb., 2005.

[10] M. Ucar and E. Ozdemir, "Control of a 3-Phase 4-Leg Active Power Filter Under Non-Ideal Mains Voltage Condition", Electric Power Systems Research, vol.78, no.1, pp.58-73, Jan., 2008.

[11] B. Singh, S. Gairola, B. Singh, A. Chandra, and K. AlHaddad, "Multipulse AC-DC Converters For Improving Power Quality: a Review", IEEE Transactions on Power Electronics, vol.23, no.1, pp.260-281, Jan., 2008.

[12] B. Singh, B. N. Singh, A. Chandra, K. Al-Haddad, A. Pandey, and D. P. Kothari, "A Review of Three-Phase 
Improved Power Quality AC-DC Converters", IEEE Transactions on industrial electronics, vol.51, no.3, pp.641-660, June, 2004.

[13] T. Friedli, M. Hartmann, and J. Kolar, "The Essence of Three-Phase PFC Rectifier Systems - Part II", IEEE Transactions on Power Electronics, vol.29, no.2, pp.543-560, Feb., 2014

[14] F. Ferreira and A. Almeida, "Induction Motor Downsizing as a Low-Cost Strategy to Save Energy", Journal of Cleaner Production, vol.24, pp.117-131, Mar., 2012.

[15] STMicroelectronics, "Sensor Field-Oriented Control (IFOC) of Three-Phase AC Induction Motors Using ST10F276", 2006. Available online: http://www.st.com/content/ccc/resource/technical/docu ment/application_note/06/30/4a/f2/c8/e3/48/e5/CD0011 6774.pdf/files/CD00116774.pdf/jcr:content/translations/ en.CD00116774.pdf (accessed on: 28-10-2020).

[16] R. Kerkman, G. Skibinski, and D. Schlegel, "AC Drives: Year 2000 (Y2K) and Beyond", Applied Power Electronics Conference and Exposition. Fourteenth Annual, vol.1, pp.28-39, Mar., 1999.

[17] D. Ross, J. Theys, and S. Bowling, "Using the dsPIC30F for Vector Control of an ACIM", Microchip Technologies, 2004. Available online: http://ww1.microchip.com/downloads/jp/AppNotes/AC IM\%20Vector\%20Control\%2000908a.pdf (accessed on: 27-10-2020).

[18] S. Bodkhe and M. Aware, "A Variable-Speed, Sensorless, Induction Motor Drive Using DC-Link Measurements", Industrial Electronics and Applications. 4th IEEE Conference on, pp.3591-3596, June, 2009.

[19] A. Parthan, L. Suresh, and J. Raj, "A Brief Review on Torque Control of Induction Motor", Circuit, Power and Computing Technologies (ICCPCT), International Conference on, pp.1-5, Apr., 2017.

[20] J. Holtz, "Sensorless Control of Induction Motor Drives", Proceedings of the IEEE, vol.90, no.8, pp.1359-1394, nov., 2002.

[21] H. Kubota and K. Matsuse, "Speed Sensorless FieldOriented Control of Induction Motor With Rotor Resistance Adaptation", IEEE Transactions on Industry Applications, vol.30, no.5, pp.1219-1224, out., 1994.

[22] M. Jamma, A. Bennassar, M. Akherraz and M. Oproescu, "An Improved Model Direct Power and Torque Control of PWM Rectifier-Inverter fed Induction Motor Drive", International Conference on Electronics, Computers and Artificial Intelligence (ECAI), Pitesti, Romania, pp.1-6, 2019.

[23] Z. Zhang, L. Wei, Y. Cui, P. S. Murthy and P. Yi, "Active EMI Reduction Technique of Active Front End (AFE) Drives Based on Randomized Switching Frequency PWM", IEEE Energy Conversion Congress and Exposition (ECCE), Baltimore, MD, USA, pp.6438-6442, 2019.

[24] E. P. Wiechmann, R. P. Burgos and D. Boboyevich, "Staggered sampling space vector modulation for multimotor AC-drive active front end converters", Proceedings of the 2000 - IEEE International Symposium on Industrial Electronics (Cat. No.00TH8543), Cholula, Puebla, Mexico, vol.1, pp.282-287, 2000.

[25] S. Leng, I. Chung, W. Liu and D. Cartes, "Reconfigurable active front-end of adjustable speed drives for power quality improvement”, IEEE Power \&
Energy Society General Meeting, Calgary, AB, pp.1-8, 2009

[26] L. Cheng, "DSP-based variable speed motor drive with power factor correction and current harmonics compensation", Intersociety Energy Conversion Engineering Conference and Exhibit (IECEC) (Cat. No.00CH37022), Las Vegas, NV, USA, vol.2, pp.1394$1399,2000$.

[27] Y. Cui and L. Wei, "Common Mode Voltage Reduction in Active Front End Drives with Different PWM Switching Frequencies for Rectifier and Inverter", IEEE Energy Conversion Congress and Exposition (ECCE), Portland, OR, pp.6424-6429, 2018.

[28] A. Videt, M. Messaoudi, N. Idir, H. Boulharts and H. Vang, "PWM strategy for common-mode voltage reduction in three-phase variable-speed drives with active front end", International Electric Drives Production Conference (EDPC), Nuremberg, pp.1-7, 2015.

[29] A. Sayed-Ahmed and R. Miklosovic, "Regenerative Active Front End based motor-drive systems with enhanced dynamic performance", IEEE Applied Power Electronics Conference and Exposition (APEC), New Orleans, LA, USA, pp.2439-2445, 2020.

[30] M. Gaiceanu and C. Nichita, "Regenerative AC drive system with the three-phase induction machine", 2014 International Conference on Applied and Theoretical Electricity (ICATE), Craiova, pp.1-6, 2014.

[31] L. Ristić, B. Brković, M. Majstorović, U. Milović, T. Taluo and M. Bebić, "Electrical Drives with Active Rectifiers Connected to Distorted Utility Grid", International Symposium on Environment-Friendly Energies and Applications (EFEA), Rome, pp.1-6, 2018.

[32] V. V. Rozhkov and V. V. Fedotov, "Improving the Properties and Characteristics of Avariable-Frequency Drive with an Active Rectifier", International Russian Automation Conference (RusAutoCon), Sochi, Russia, pp.903-907, 2020

[33] L. Machado, Tiago J. C. Sousa, D. Pedrosa, V. Monteiro, G. Pinto, J. L Afonso, "A Three-Phase Bidirectional Variable Speed Drive: An Experimental Validation for a Three-Phase Induction Motor", Sustainable Energy for Smart Cities, pp.47-57, Apr., 2020.

[34] P. Rongmei, S. Shimi, D. Chatterji, and V. Sharma, "A Novel Fast Braking System For Induction Motor", International Journal of Engineering and Innovative Technology (IJEIT), vol.1, no.6, pp.65-69, June, 2012.

[35] M. Gaiceanu and C. Nichita, "Regenerative AC Drive System With The Three-Phase Induction Machine", Applied and Theoretical Electricity (ICATE), out., 2014.

[36] S. Murthy, G. Berg, C. Jha, and A. Tandon, "A Novel Method of Multistage Dynamic Braking of Three-Phase Induction Motors", IEEE transactions on industry applications, no.2, pp.328-334, Mar., 1984.

[37] C. Phipps and F. Press, Variable Speed Drive Fundamentals. Fairmont Press, no.3, 1999. ISBN: 088173-310-5.

[38] B. Sampurno, A. Abdurrakhman, and H. Hadi, "Development of Electrical Kinetic Energy Recovery System (KERS) on Motorcyle", Advanced Mechatronics, Intelligent Manufacture, and Industrial Automation (ICAMIMIA), pp.131-136, out., 2015. 
[39] Alberto Boretti, "Kinetic Energy Recovery Systems for Racing Cars", SAE, pp.49-49, 2013.

[40] S. Agrawal, V. Kumar, A. Alam, and P. Thakura, "Regenerative Braking For Induction Motor Drive", Power India International Conference (PIICON), 6th IEEE, pp.1-6, Dec., 2014.

[41] J. Zhang, X. Lu, J. Xue, and B. Li, "Regenerative Braking System For Series Hybrid Electric City Bus", The World Electric Vehicle Journal, vol.2, no.4, pp.128-134, Dec., 2008.

[42] L. Rolim, D. da Costa, and M. Aredes, "Analysis and Software Implementation of a Robust Synchronizing PLL Circuit Based On The pq Theory", IEEE Transactions on Industrial Electronics, vol.53, no.6, pp.1919-1926, Dec., 2006.

[43] T. Thacker, D. Boroyevich, R. Burgos, and F. Wang, "Phase-Locked Loop Noise Reduction Via Phase Detector Implementation For Single-Phase Systems", IEEE Transactions on Industrial Electronics, vol.58, no.6, pp.2482-2490, June, 2011.

[44] S. Golestan, M. Monfared, F. Freijedo, and J. Guerrero, "Design And Tuning of a Modified Power-Based PLL For Single-Phase Grid-Connected Power Conditioning Systems", IEEE Transactions on Power Electronics, vol.27, no.8, pp.3639-3650, Aug., 2012.

[45] S. Golestan, J. Guerrero, and J. Vasquez, "Three-Phase PLLs: A Review of Recent Advances", IEEE Transactions on Power Electronics, vol.32, no.3, pp.1894-1907, Mar., 2017.

[46] X. Guo, W. Wu, and H. Gu, "Phase Locked Loop And Synchronization Methods For Grid-Interfaced Converters: a Review", Przeglad Elektrotechniczny, vol.87, no.4, pp.182-187, Jan., 2011.

[47] S. Bosch, J. Staiger, and H. Steinhart, "Predictive Current Control for an Active Power Filter with LCLFilter", IEEE Transactions on Industrial Electronics, June, 2017.

[48] J. Pinto, "Nova Topologia de UPQC sem Transformador para Compensação de Problemas de Qualidade de Energia Elétrica", Doctoral thesis, University of Minho, Guimarães, 2011.

[49] K. Kumar, P. Michael, J. John, and S. Kumar, "Simulation and Comparison of SPWM and SVPWM Control For Three Phase Inverter", ARPN Journal of Engineering and Applied Sciences, vol.5, no.7, pp.6174, Jul., 2010.

[50] V. Bacon, L. Campanhol, and S. Silva, "Análise Comparativa das Técnicas SPWM e SVM Aplicadas a um Inversor de Tensão Trifásico", UNOPAR Científica Ciências Exatas e Tecnológicas, vol.10, no.1, nov., 2015. [Online]. Available in: http://www.pgsskroton.com.br/seer/index.php/exatas/art icle/view/508/479. [Accessed: 28-May-2017].

[51] K. Tembhekar, "Improvement And Analysis of Speed Control of Three Phase Induction Motor Drive Including Two Methods", Emerging Trends in Engineering and Technology (ICETET), 2nd International Conference on, pp.736-741, 2009.

[52] D. Ross, J. Theys, and S. Bowling, "Using the dsPIC30F for Vector Control of an ACIM", Microchip Technologies, 2004. Available online: http://ww1.microchip.com/downloads/jp/AppNotes/AC IM\%20Vector\%20Control\%2000908a.pdf (accessed on: 28-10-2020).

[53] S. Bodkhe and M. Aware, "A Variable-Speed, Sensorless, Induction Motor Drive Using DC-Link
Measurements", Industrial Electronics and Applications. 4th IEEE Conference on, pp.3591-3596, June, 2009.

[54] H. M. D. Habbi, H. J. Ajeel, and I. I. Ali, "Speed Control of Induction Motor using PI and V/F Scalar Vector Controllers", International Journal of Computer Applications, vol.151, no.7, Oct., 2016.

[55] Delfim Pedrosa, Rui Pereira, Henrique Gonçalves, Bruno Exposto, Vítor Monteiro, J. G. Pinto, João L. Afonso, "Development of a Digital Controller with Data Acquisition to a Test Bench for Eletric Motors", SAAEI 2012 - Annual Seminar on Automation, Industrial Electronics and Instrumentation, Guimarães, Portugal, pp.458-463, July, 2012. 